\section{Atopisches Ekzem: Cremen und Salben hilft allenthalben}

Düsseldorfer Dermatologen wollten es wissen: Wenn eine gestörte Barrierefunktion der Haut das Eindringen von Aeroallergenen, z. B. von Hausstaubmilben, und damit die Ekzementstehung begünstigt, kann dann die richtige Pflege Ekzemen vorbeugen?

A n der Studie der Universitätshautklinik Düsseldorf nahmen 40 Patienten (Alter: 18 bis 83 Jahre) mit atopischem Ekzem in Remission teil. Sie cremten sich sieben Tage lang mit einer Ö/W-Emulsion einen Oberarm ein, den anderen aber nicht. Am achten Tag brachte man Atopie-Patch-Tests (als Modell für die Auslösephase des atopischen Ekzems) mit Allergenextrakten von Hausstaubmilbe (D. pteronyssinus) und Wiesenlieschgras an beiden Oberarmen auf. Die Patienten hatten auf mindestens eines der beiden Allergene im Prick-Test eine Soforttypreaktion gezeigt. Die Untersucher lasen den Atopie-Patch-Test nach 20 Minuten sowie nach 24 und 48 Stunden ab.

Es ergaben sich sowohl nach 24 als auch nach 48 Stunden signifikante Unterschiede in der Reaktivität: Die mit der Ö/W-Emulsion vorbehandelte Haut reagierte seltener oder schwächer als die unbehandelte Haut.

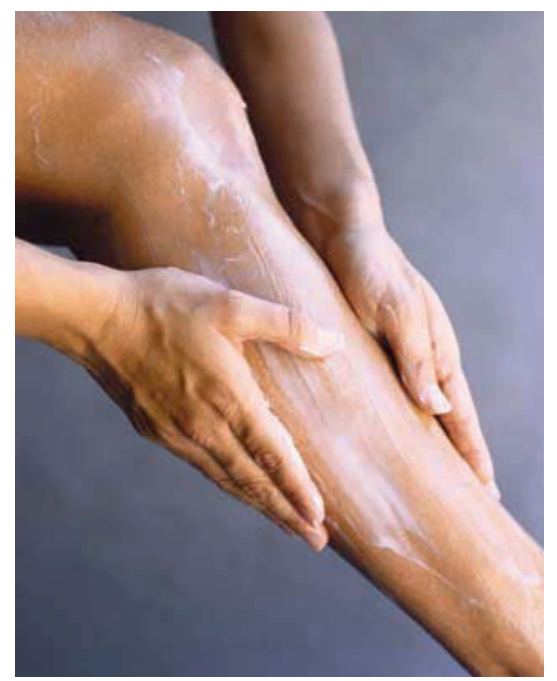

Atopisches Ekzem: Durch intensive Pflege lässt sich das Eindringen von Aeroallergenen verringern.

\section{Fazit}

Die Studie zeigt, dass eine Vorbehandlung mit einer Ö/W-Emulsion die Ekzementstehung durch Hautkontakt mit Aeroallergenen verhindern könnte. $\mathrm{Ob}$ auch andere Produkte als die untersuchdoch allergisch sein könnte.
Es wurden 20 Patienten mit Reiz- darmsyndrom und Beschwerden nach Verzehr von Weizenprodukten untersucht, von denen zehn Atopiker waren. Nach Einhalten einer weizenfreien Karenzzeit wurden orale Provokationstests mit $80 \mathrm{~g}$ gekochter Pasta durchgeführt, welche die Unverträglichkeit belegten. Positive Hautreaktionen und spezifische Serum-IgE-Antikörper gegen Weizenmehl hatten alle zehn atopischen Patienten, aber nur jeweils einer der nicht atopischen Probanden.

Mit den Seren der Patienten wurden dann Immunoblotuntersuchungen mit speziell aufbereiteten Proteinfraktionen von Weizenmehl durchgeführt. Dabei konnten bei allen Patienten spezifische IgE-Antikörper gegen verschiedene Weizenproteine nachgewiesen werden. Im Gegensatz zu atopischen Patienten, bei denen sich häufig Reaktionen auf $\alpha$-Amylase-Trypsin-Inhibitoren fanden, hatten nicht atopische $\mathrm{Pa}$ tienten mit gastrointestinalen Symptomen häufig spezifische Serum-IgE-Antikörper auf Proteine der ProlaminFraktion. Bei alleiniger Durchführung

te Zubereitung diesen Effekt erreichen können und welche klinische Relevanz er besitzt, bleibt vorläufig offen. In jedem Fall stützen die Befunde die übliche therapeutische Empfehlung an Patienten mit atopischem Ekzem, in der Remissionsphase der Erkrankung durch „hautpflegende“ Externa Rezidivprophylaxe zu betreiben.

Dr. A. Niedermeier, München

Billmann-Eberwein C et al. Modulation von Atopie-Patch-Testreaktionen durch die topische Behandlung der Haut mit einem hautverwandte Lipide enthaltenden Externum. Dermatol Beruf Umwelt 2001; 49: $193-7$

\title{
Negativer Hauttest, keine IgE-Antikörper - trotzdem Nahrungsmittel-Allergie
}

Wissenschaftler der Universität Padua befassten sich mit der Frage, ob ein Reizdarmsyndrom nach Genuss von Weizenprodukten nicht

von Hauttests und IgE-Antikörperbestimmung mittels CAP-FEIA wäre bei $50 \%$ dieser Patienten anstelle einer Nahrungsmittelallergie eine Nahrungsmittelintoleranz diagnostiziert worden.

\section{Fazit}

Nach wie vor sind sorgfältige Anamnese, Eliminationsdiät und anschließender Provokationstest die diagnostischen Säulen zur Aufdeckung einer Nahrungsmittelallergie. Die verfügbaren Allergenpräparationen scheinen bei nicht atopischen Patienten mit gastrointestinaler Symptomatik zur Diagnose einer Weizenmehlallergie nicht gut geeignet zu sein. Diese Befunde sollten weiter gesichert werden. Vor allem ist zu fragen, wie oft hinter einem Reizdarmsyndrom doch eine Nahrungsmittel-Allergie steckt. Dr. A. Niedermeier, München

Simonato B et al. IgE binding to soluble and insoluble wheat flour proteins in atopic and non-atopic patients suffering from gastrointestinal symptoms after wheat ingestion. Clin Exp Allergy 2001; 31: 1771-8 